\title{
Prostate Cancer Screening: A Complicated Puzzle, Explanation Needed
}

\author{
Barak Gaster, MD
}

Department of Medicine, University of Washington, Seattle, WA, USA.

$\mathrm{J}$ Gen Intern Med 28(12):1549-50

DOI: $10.1007 / \mathrm{s} 11606-013-2542-\mathrm{x}$

(c) Society of General Internal Medicine 2013

$\mathrm{O}$ $\mathrm{f}$ all the common medical decisions people make, perhaps the least understood is whether to be screened for prostate cancer. For years, the uncertainty was chalked up to the lack of clinical trial data. But two landmark studies in the past year, involving over 200,000 men, provide clear evidence that if there is a benefit from prostate cancer screening, it is small, and it may be outweighed by the potential harms brought about by screening. ${ }^{1,2}$

It wasn't supposed to be this way. Once all the data was in, we were supposed to have a clearer idea whether this was a good test or not. Instead, updated guidelines released last April from the American College of Physicians reaffirmed that rather than recommending for or against screening, clinicians should inform men about the complex pros and cons, and prostate-specific antigen (PSA) tests should be ordered only for men who express a clear preference for screening. ${ }^{3}$ The facets of the decision remain hard to explain, and many doctors still order PSA blood tests without discussing the possible downsides of screening. ${ }^{4}$ Others fail to mention the test at all, setting many of their patients up for a possible surprise, given that $3 \%$ of men under their care will eventually die of prostate cancer. ${ }^{5}$

The root of the uncertainty is that prostate cancer is generally a very slow-growing cancer. Unlike cancers of the lung, breast, and colon, the majority of men with prostate cancer live with it for 20,30 , or even 40 years, never knowing that they have it, eventually dying of something else. ${ }^{6}$

But $3 \%$ of men do die of prostate cancer. So why not check for it? Because not only is prostate cancer usually slow growing, but the treatments for it carry high risks of significant long-term side effects, especially urinary incontinence and erectile dysfunction. ${ }^{7}$ Despite decades of research, we're still not good at predicting the future behavior of a given prostate cancer, or of being able to treat prostate cancer without damaging nearby organs. So we end up treating most of the cancers we find and incurring lots of harm and expense in the process. ${ }^{8,9}$

Some patients reasonably ask, "Why not just get a PSA blood test, and I'll decide later what do if we get a bad result?" While this sounds reasonable, it's important to explain to patients that it's better to discuss up front whether their PSA result is information they want to have, because it's so difficult psychologically to not follow-up a result that might indicate cancer and to not treat a cancer once it's found.

So what should we tell patients? A concise explanation might sound something like this:

"Prostate cancer is an unusual cancer that rarely causes problems. And the treatments for prostate cancer cause many side effects. So screening for prostate cancer might cause harm, since the treatment might be worse than the disease. That said, some men do die from prostate cancer. And there is a small chance that screening might prolong your life some. So getting a PSA test might make sense for some men. But for many others it makes more sense to decide not be screened. What do you think?"

Additional points to consider are the high risk of false positive PSA tests leading to painful prostate biopsies, and the psychological harm men might suffer from having to fight an unnecessary "battle with cancer."

Why do primary care providers have a hard time discussing these pros and cons? Not only are they complicated to explain, but many physicians may feel psychological unease about "missing cancer," feeling that it's safer to just continue ordering routine PSA tests automatically despite the uncertainties. Although this can partly be explained by physicians' fear of being sued from missing cancer, it is also a simple human desire to "not let my patients down," since regardless of whether or not a man is screened, there is still a $3 \%$ chance that he will die from prostate cancer. So if the decision is made not to screen, down the road patients and doctors might look back with great regret, wishing that they had ordered a PSA. 
Cultural forces also play a role in keeping screening rates high. Famous prostate cancer survivors become advocates for screening, telling of life threatening diagnoses followed by lifesaving cures. Their stories are certainly more compelling than those of the men who don't get tested, many of whom live long lives unaware of inconsequential prostate cancers, who don't know that they have a story to tell at all.

So despite expert guidelines discouraging routine prostate cancer screening, the public still hears mostly the advertisements from retired sports stars urging men to "get tested". But the truth is more complicated. And it's crucial that primary care providers get comfortable explaining this puzzle to men, as men deserve to hear the whole story.

Conflict of Interest: The author declares no conflicts of interest.

Corresponding Author: Barak Gaster, MD; Department of Medicine, University of Washington, 4245 Roosevelt Way NE, Seattle, WA 98105-6920, USA (e-mail: barakg@uw.edu).

\section{REFERENCES}

1. Andriole GL, Crawford ED, Grubb RL, et al. Prostate cancer screening in the randomized Prostate, Lung, Colorectal, and Ovarian Cancer Screening Trial: mortality results after 13 years of follow-up. J Natl Cancer Inst. 2012;104(2):125-32.

2. Schröder FH, Hugosson J, Roobol MJ, et al. Prostate-cancer mortality at 11 years of follow-up. N Engl J Med. 2012;366(11):981-90.

3. Gaseem A, Barry MJ, Denberg TD, et al. Screening for prostate cancer: a guidance statement from the clinical guidelines committee of the American College of Physicians. Ann Intern Med. Published online April 9, 2013.

4. Linder SK, Hawley ST, Cooper CP, Scholl LE, Jibaja-Weiss M, Volk RJ. Primary care physicians' reported use of pre-screening discussions for prostate cancer screening: a cross-sectional survey. BMC Fam Pract. 2009; 10: 19 .

5. Siegel R, Naishadham D, Jemal A. Cancer statistics, 2012. CA Cancer J Clin. 2012;62(1):10-29.

6. Chou R, Croswell JM, Dana T, et al. Screening for Prostate Cancer: A Review of the Evidence for the U.S. Preventive Services Task Force. Ann Intern Med. 2011;155:762-71.

7. Sanda MG, Dunn RL, Michalski J, et al. Quality of life and satisfaction with outcome among prostate-cancer survivors. N Engl J Med. 2008;358(12):1250-61.

8. Ip S, Dahabreh IJ, Chung $\mathbf{M}$, et al. An evidence review of active surveillance in men with localized prostate cancer. Evidence Report/ Technology Assessment No. 204. AHRQ Publication No. 12-E003-EF. Rockville, MD: Agency for Healthcare Research and Quality. December 2011.

9. Heijnsdijk EA, Wever EM, Auvinen A, et al. Quality-of-life effects of prostate-specific antigen screening. N Engl J Med. 2012;367(7):595-605. 